\title{
Crescimento e produtividade da bananeira cv. Grande Naine sob diferentes combinações de nitrato de cálcio e ureia
}

\author{
Márcio da Silva Alves ${ }^{1}$, Eugênio Ferreira Coelho², Vital Pedro da Silva Paz ${ }^{3}$, Torquato Martins de Andrade Neto ${ }^{4}$
}

\section{RESUMO}

A utilização de fontes nitrogenadas via fertirrigação requer que as técnicas de manejo da aplicação sejam aperfeiçoadas, de modo que os produtores possam obter o máximo benefício econômico, combinado com um menor impacto no solo ao se utilizarem esses fertilizantes. O objetivo deste trabalho foi avaliar diferentes combinações de duas fontes nitrogenadas aplicadas por fertirrigação sobre o crescimento e a produtividade da bananeira Grande Naine no primeiro, segundo e terceiro ciclos de produção. O delineamento experimental foi em blocos ao acaso, com cinco repetições em que se utilizaram seis percentagens complementares de ureia e nitrato de cálcio, aplicados via água de irrigação em sistema de gotejamento. As variáveis avaliadas foram: altura da planta, diâmetro do pseudocaule e área foliar total, além de produtividade, comprimento e diâmetro do fruto da segunda penca. Os resultados indicaram que as diferentes combinações das fontes nitrogenadas aplicadas por fertirrigação não tiveram efeito sobre a produtividade e o crescimento da bananeira Grande Naine.

Palavras-chave: Adubação nitrogenada, nitrogenio, fertirrigação

\section{ABSTRACT}

\section{Growth and yield of banana crop under different combinations of calcium nitrate and urea}

The use of nitrogen sources through fertigation requires improved techniques so that farmers may obtain maximum economic benefit combined with lower soil impact. The objective of this work was to evaluate different combinations of two nitrogen sources applied by fertigation on the growth and yield of banana cv. Grand Naine during the first, second and third production cycles. The experiment was arranged in a randomized block design with five replications, where six complementary percentages of urea and nitrate were applied by irrigation water in a drip irrigation system. Plant height, pseudostem diameter, total leaf area, productivity, fruit length and diameter of the second bunch were evaluated. Results showed that the combination of different nitrogen sources applied by fertigation did not affect the growth and yield of cv. Grand Naine.

Key words: Nitrogen fertilizer, nitrogen, fertirrigation.

\footnotetext{
Recebido para publicação em agosto de 2008 e aprovado em julho de 2009

${ }^{1}$ Engenheiro-Agrônomo, Mestre. Doutorando da Universidade Federal do Recôncavo da Bahia (UFRB), Centro de Ciências Agrárias, Ambientais e Biológicas, Campus Universitário s/n Centro, 44380-000, Cruz das Almas, Bahia, Brasil. marciodv@yahoo.com.br

22, Engenheiro-Agrônomo, Doutor. Pesquisador da Embrapa Mandioca e Fruticultura, Rua da Embrapa s/n, Chapadinha, 44380-000, Cruz das Almas, Bahia, Brasil. eugenio@cnpmf.embrapa.br

${ }^{3}$ Engenheiro-Agrônomo, Doutor. Universidade Federal do Recôncavo da Bahia, Centro de Ciências Agrárias, Ambientais e Biológicas, Campus Universitário s/n Centro, 44380000, Cruz das Almas, Bahia, Brasil. vitalpaz@ufrb.edu.br

${ }^{4}$ Engenheiro-Agrônomo. Mestrando em Ciências Agrárias, da Universidade Federal do Recôncavo da Bahia, Centro de Ciências Agrárias, Ambientais e Biológicas, Campus Universitário s/n Centro, 44380-000, Cruz das Almas, Bahia, Brasil. tormantinandrade@yahoo.com.br
} 


\section{INTRODUÇÃO}

A bananeira é uma planta originária do continente Asiático, e no Brasil é cultivada de Norte a Sul, em regiões tropicais e subtropicais. A safra 2006/07 brasileira de bananas, conforme o IBGE (2007), registrou produção de 7,098 milhões de toneladas, área plantada de 519,187 mil hectares, área colhida de 515,346 mil ha e produtividade média de 13,773 ton ha-1.

O nitrogênio é um dos nutrientes mais absorvidos e necessários para o crescimento e a produção da bananeira, pela elevada quantidade absorvida e exportada pelos frutos (Borges et al., 1997; Silva et al., 1999), além de ser um dos mais aplicados via água de irrigação, pois apresenta alta mobilidade no solo, principalmente na forma de nitrato (Borges \& Coelho 2002). No entanto, deve-se ter especial atenção quanto ao uso desse nutriente, visando aumentar a eficiência de sua utilização, quantificando níveis adequados e conhecendo a magnitude e a velocidade das suas transformações.

Na fertilização nitrogenada as fontes rapidamente disponíveis são sais inorgânicos de amônio, nitrato e ureia, sendo as mais utilizadas a uréia e o sulfato de amônio (Barbosa Filho et al., 2004). Contudo, a utilização dessas fontes requer aperfeiçoamento nas técnicas de manejo da aplicação, de modo que os produtores possam obter o máximo de benefício econômico ao utilizar esses fertilizantes.

O nitrogênio, devido à grande suscetibilidade às condições ambientais e ao papel que ele desempenha no aumento e na queda de produção, é um elemento que apresenta as maiores dificuldades de manejo. Segundo Thornley (1972), a deficiência de nitrogênio, além de reduzir o crescimento, pode afetar a partição de assimilados entre as diferentes partes da planta, ocasionando, via de regra, aumento na relação entre a massa seca das raízes e a massa seca da parte aérea. Na bananeira, o nitrogênio é responsável pelo aumento do número de pencas e pela emissão e crescimento dos rebentos, aumentando consideravelmente a quantidade total de massa seca (Lahav \& Turner, 1983). Borges et al. (2002) não detectaram efeito significativo de doses crescentes de $\mathrm{N}$ mineral e adubo orgânico nas variáveis de crescimento (altura da planta, diâmetro e número de folhas vivas) e de produtividade da bananeira, sendo em média 34,1 t ha ${ }^{-1}$. Brasil et al. (2000), avaliando o efeito da adubação nitrogenada em três níveis de N/planta/ano, utilizandose como fonte a ureia, observaram que o $\mathrm{N}$ promoveu aumento linear no peso dos cachos e das pencas por cacho e peso médio das pencas.

A aplicação via água de irrigação permite o parcelamento desse nutriente de acordo com a demanda da cultura, reduzindo as perdas e o custo de produção. Por ser um nutriente altamente móvel no solo e requerido em quantidades relativamente elevadas, deve merecer especial aten- ção em sistemas de cultivo irrigados, visando aumentar a eficiência de sua utilização. Portanto, além de se quantificar níveis adequados de água e nitrogênio, é necessário conhecer a magnitude e a velocidade das transformações desse nutriente no solo (Coelho, 1994).

A dinâmica do nitrogênio é influenciada por sua fonte, e no caso das fontes amídicas e amoniacais, ele ocorrerá no solo em forma de amônio inicialmente e de nitrato posteriormente; no caso da fonte nítrica, ele ocorrerá em forma de nitrato, o que indica maior mobilidade no solo, com possibilidades inclusive de lixiviação (Coelho et al., 2001).

O uso das fontes amoniacais traz, apesar da vantagem do menor custo, uma desvantagem da possível redução no pH e na saturação de bases do solo, diminuindo a disponibilidade de nutrientes e, consequentemente, reduzindo a produtividade. Uma forma de contornar esse problema é o uso de uma fonte amoniacal conjugada com uma fonte nítrica.

Haynes \& Swift (1987) estudaram o efeito da aplicação de nitrato de cálcio, sulfato de amônio e ureia em duas doses, por meio de sistemas irrigados por gotejamento sobre o crescimento e a produção do mamoeiro. Os autores verificaram aumento no crescimento e na produção do mamoeiro com a aplicação de nitrogênio. No entanto, o crescimento foi maior na menor dose de nitrogênio (100 kg de $\mathrm{N}_{\text {ha }}{ }^{-1}$ ) na seguinte ordem: nitrato de cálcio, uréia e sulfato de amônio. Já a produtividade foi maior com a aplicação de ureia (200 kg de $\mathrm{N} \mathrm{ha}^{-1}$ ), seguida do sulfato de amônio e, por último o nitrato de cálcio.

Souza et al. (2007), estudando o crescimento e a produtividade do mamoeiro em diferentes combinações de fontes nitrogenadas nitrato de cálcio e sulfato de amônio, verificaram que os componentes biométricos (altura de planta, diâmetro de caule e área foliar), assim como o número de frutos e a produtividade do mamoeiro, não foram influenciados pelas diferentes combinações de fontes nitrogenadas aplicadas à planta, via água de irrigação.

Este trabalho teve como objetivo avaliar diferentes combinações de duas fontes nitrogenadas, amoniacal e nítrica, aplicadas por fertirrigação sobre o crescimento em dois ciclos de produção e a produtividade da bananeira Grande Naine no primeiro, segundo e terceiro ciclos de produção.

\section{MATERIAL E METODOS}

O experimento foi realizado na EMBRAPA Mandioca e Fruticultura, no município de Cruz das Almas, região do Recôncavo Baiano, a 12 40’19" de latitude sul, 3906' 23" de longitude oeste $\mathrm{Gr}$ e altitude de $225 \mathrm{~m}$. O clima da região é classificado como úmido a subúmido, com umidade relativa e temperatura média anuais de $80 \%$ e $24{ }^{\circ} \mathrm{C}$, respectivamente, e pluviosidade média anual de $1.143 \mathrm{~mm}$ (D’Angiolella et al., 1998).

O solo é um Latossolo Amarelo álico coeso, de textura média, contendo $529 \mathrm{~g}$ de areia $\mathrm{kg}^{-1}, 107 \mathrm{~g}$ de silte $\mathrm{kg}^{-1}, 364$ 
g de argila $\mathrm{kg}^{-1}$ e densidade de $1,51 \mathrm{~kg} \mathrm{dm}^{-3}$ (Souza \& Souza, 2001). A umidade do solo correspondente à capacidade de campo é $0,23 \mathrm{~m}^{3}, \mathrm{~m}^{-3}$ equivalente a tensão de -10 $\mathrm{kPa}$, e a umidade no ponto de murcha permanente é de $0,16 \mathrm{~m}^{3} \mathrm{~m}^{-3}$, equivalente à tensão de $-1.500 \mathrm{kPa}$. As propriedades químicas amostradas na profundidade 0-0,20 e 0,20-0,40 m são apresentadas na Tabela 1 .

O preparo do solo consistiu na aração, gradagem e calagem, sendo aplicados $1600 \mathrm{~kg} \mathrm{ha}^{-1}$ de calcário dolomítico. As covas foram abertas nas dimensões de 0,5 x 0,5 x 0,5 m. Cada uma recebeu uma mistura de $105 \mathrm{~g}$ de superfosfato simples, 50 g de FTE BR-12 e 20 L de esterco de curral, conforme recomendação de Borges (2004).

O cultivar utilizado para o estudo foi a Grande Naine (grupo genômico AAA, subgrupo Cavendish), usandose mudas do tipo chifre, com aproximadamente $30 \mathrm{~cm}$ de altura. O delineamento experimental foi em blocos casualisados, com seis tratamentos, cinco repetições e nove plantas por unidade experimental, sendo seis tomadas como úteis com espaçamento de 2,5 x 3,0 m.

O nitrogênio ( $\mathrm{N}$ ) foi aplicado com base em recomendação de Borges \& Costa (2002), correspondendo a $300 \mathrm{~kg}$ $\mathrm{ha}^{-1}$. ano-1 no primeiro ciclo e $275 \mathrm{~kg} \mathrm{ha}^{-1} \mathrm{ano}^{-1}$ no segundo e terceiro ciclos. Além do nitrogênio, aplicou-se potássio $\left(\mathrm{K}_{2} \mathrm{O}\right)$ via água de irrigação na dose de $750 \mathrm{~kg} \mathrm{ha}^{-1} \mathrm{ano}^{-1}$ no primeiro, segundo e terceiro ciclos, de acordo com recomendação de Borges \& Costa (2002). As quantidades de nitrogênio foram convertidas para as fontes de ureia (fonte amídica) e nitrato de cálcio (fonte nítrica). Em cada ciclo da cultura, inicialmente, aplicou-se uma percentagem do nitrogenio total na forma de uréia, conforme o tratamento, seguido da aplicação do restante do nitrogenio total na forma de nitrato de cálcio. Os tratamentos foram: T1 = 100\% do ciclo com aplicação do nitrogênio total na forma de ureia; T2 = 80\% do ciclo com aplicação do nitrogênio total na forma de ureia e $20 \%$ com aplicação na forma de nitrato de cálcio; T3 = 60\% do ciclo com aplicação do nitrogênio total na forma de ureia e 40\% com aplicação na forma de nitrato de cálcio; T4 = 40\% do ciclo com aplicação do nitrogênio total na forma de ureia e 60\% com aplicação na forma de nitrato de cálcio; T5 = 20\% do ciclo com aplicação do nitrogênio total na forma de ureia e 80\% com aplicação na forma de nitrato de cálcio; e T6 = 100\% do ciclo com aplicação do nitrogênio total na forma de nitrato de cálcio (Tabela 2).
A necessidade hídrica da cultura foi determinada pela evapotranspiração potencial de referência (ETo), em milímetros, estimada pelo método do tanque Classe A, utilizando o coeficiente do tanque (Kp) segundo Doorembos \& Pruitt (1977), localizado próximo à área experimental. Os valores dos coeficientes de cultura (Kc) foram adotados de acordo com o desenvolvimento da cultura segundo Doorembos \& Kassam (1979).

As irrigações foram realizadas com turno de rega de um dia. Os fertilizantes foram aplicados por fertirrigação, em duas aplicações semanais, utilizando-se uma bomba injetora hidráulica (TMB 60) com vazão de $60 \mathrm{~L} \mathrm{~h}^{-1}$, onde os tratamentos foram diferenciados por meio de registros na entrada da área experimental.

O sistema de irrigação utilizado foi gotejamento, com uma linha lateral por fileira e três gotejadores por planta, com vazão de 3,75 $\mathrm{L} \mathrm{h}^{-1}$ cada. A umidade foi monitorada utilizando sondas de TDR fabricadas artesanalmente em laboratório com 0,10 m de comprimento de haste e 0,0032 $\mathrm{m}$ de diâmetro, de aço inox. Essas sondas foram instaladas nos blocos e em todos os tratamentos a 0,20; 0,40; e $0,60 \mathrm{~m}$ de profundidade, a uma distância de $0,30 \mathrm{~m}$ da touceira. Foi utilizada no monitoramento a TDR 100 da Campbell Scientific Inc., empregando-se o modelo de Ledieu et al. (1986) para determinar a constante dielétrica aparente $(\varepsilon)$ dada pela equação: $\theta=0,1138 \sqrt{\varepsilon}-0,1758$. Para a conversão da constante dielétrica aparente em umidade volumétrica, realizou-se uma calibração das sondas, conforme Coelho et al. (2001), obtendo-se a equação polinomial cúbica da umidade gravimétrica è como função da constante dielétrica do solo: $\theta=-0,00001 \varepsilon^{3}+$ $0,001 \varepsilon^{2}-0,0287 \varepsilon+0,4505$.

Para análise de crescimento foram avaliados a altura da planta (da superfície do solo ao início do engaço), o diâmetro do pseudocaule a $0,20 \mathrm{~m}$ da superfície do solo e a área foliar total (AF), esta estimada a partir da leitura do comprimento e da largura da terceira folha ( folha nova), conforme Alves et al. (2001), ou seja:

$$
A F=0,901 *(\mathrm{l} * \mathrm{~W})^{1,2135}
$$

Em que:

$A F=$ área foliar total da planta, em $\mathrm{cm}^{2}$;

$L$ = largura máxima da terceira folha, em cm; e

$W=$ comprimento da terceira folha, em $\mathrm{cm}$.

Tabela 1. Características químicas do solo Latossolo Amarelo álico coeso da área experimental no município de Cruz das Almas, Bahia

\begin{tabular}{|c|c|c|c|c|c|c|c|c|c|c|}
\hline $\begin{array}{l}\text { Profundidade } \\
\text { (m) }\end{array}$ & $\begin{array}{c}\mathrm{pH} \\
\left(\mathrm{em} \mathrm{H}_{2} \mathrm{O}\right)\end{array}$ & $\begin{array}{c}P \\
\left(\mathrm{mg} \mathrm{dm}^{-3}\right)\end{array}$ & $\mathbf{K}$ & Ca & $\begin{array}{l}\text { Mg } \\
\text { olc d }\end{array}$ & $\mathrm{Na}$ & $\mathbf{S}$ & CTC & $\begin{array}{l}\mathrm{V} \\
\%\end{array}$ & $\begin{array}{l}\text { M.O. } \\
\text { g kg }^{-1}\end{array}$ \\
\hline $0-0,20$ & 5,17 & 4,33 & 0,26 & 1,17 & 1,27 & 0,14 & 2,83 & 5,95 & 47 & 7,54 \\
\hline $0,20-0,40$ & 5,27 & 4,33 & 0,33 & 1,30 & 1,07 & 0,15 & 2,85 & 5,85 & 48 & 7,31 \\
\hline
\end{tabular}


Tabela 2. Quantidade aplicada das fontes de Uréia e Nitrato de Cálcio (NC) por tratamento no primeiro e segundo ciclos de produção da bananeira cv. Grande Naine

\begin{tabular}{|c|c|c|c|c|}
\hline \multirow{4}{*}{ Tratamento } & \multicolumn{4}{|c|}{ Total de fontes de Nitrogênio aplicado } \\
\hline & \multicolumn{2}{|c|}{$1^{\circ}$ ciclo } & \multicolumn{2}{|c|}{$2^{\circ}$ ciclo } \\
\hline & Uréia & NC & Uréia & NC \\
\hline & \multicolumn{2}{|c|}{$\left(\mathrm{kg} \mathrm{ha}^{-1}\right)$} & \multicolumn{2}{|c|}{$\left(\mathrm{kg} \mathrm{ha}^{-1}\right)$} \\
\hline $\mathrm{T} 1$ & 622,69 & 0,0 & 569,32 & 0,0 \\
\hline $\mathrm{T} 2$ & 544,85 & 250,19 & 474,43 & 304,35 \\
\hline T3 & 428,10 & 625,47 & 332,10 & 763,48 \\
\hline $\mathrm{T} 4$ & 350,26 & 875,66 & 237,22 & 1067,47 \\
\hline T5 & 124,54 & 1601,20 & 94,89 & 1524,95 \\
\hline T6 & 0,0 & 2001,50 & 0,0 & 1829,94 \\
\hline
\end{tabular}

As medidas foram tomadas no período de emissão dos cachos apenas nos dois primeiros ciclos. As variáveis de produção foram obtidas no momento da colheita, quando o fruto central da segunda penca atingiu cerca de 34 a 36 mm de diâmetro e a coloração da casca passou de verde escuro intenso para verde mais claro. Avaliaram-se o peso total de pencas por hectare (produtividade de pencas), o número de frutos por cacho, o comprimento e o diâmetro do fruto central da segunda penca. Essas variáveis foram medidas nos três ciclos da cultura. Realizou-se a análise de variância dos dados biométricos e de produção, empregando-se o programa estatístico SAS (2000).

Realizou-se a análise de custo da utilização das fontes nas diferentes combinações aplicadas via água de irrigação, examinando o custo variável como sendo a quantidade de adubos gastos em cada tratamento, a receita bruta como o produto do rendimento médio pelo preço recebido pelo produtor e a margem bruta gerada pela diferença entre receita bruta e custo variável dos tratamentos. Os preços médios dos fertilizantes foram coletados na região em dezembro 2007. Para calcular os indicadores econômicos da cultura da bananeira foi considerado o preço médio recebido pelo produtor de $\mathrm{R} \$ 0,30 / \mathrm{kg}$ na região do estudo. O custo da fonte nitrato de cálcio foi de $\mathrm{R} \$ 2,60 \mathrm{~kg}^{-1}$, enquanto o da ureia foi de $\mathrm{R} \$ 1,10 \mathrm{~kg}^{-1}$.

\section{RESULTADOS E DISCUSSÃO}

No primeiro ciclo foi observado o efeito significativo dos tratamentos apenas para área foliar total, em que a aplicação apenas do Nitrato de Cálcio (T6) em todo ciclo da cultura promoveu maiores valores em relação aos outros tratamentos. Observou-se ainda que nos dois primeiros ciclos, tratamentos T4, T5 e T6, em que a maior parte do ciclo foi fertirrigado com nitrato de cálcio, a área foliar total da planta resultou em valores superiores aos tratamentos T1, T2 e T3, em que a maior parte do ciclo foi fertirrigado com ureia (Tabela 3).
Verificou-se, ainda, que no primeiro ciclo os parâmetros biométricos medidos foram inferiores aos encontrados por Silva et al. (2000) que são de aproximadamente 2 a $3 \mathrm{~m}$ para a altura da planta, $12 \mathrm{~m}^{2}$ para a área foliar e de $0,02 \mathrm{a}$ 0,03 m para o diâmetro do pseudocaule. Isso provavelmente ocorreu devido a problemas de desuniformidade observados nas mudas por ocasião do plantio, o que levou à avaliação de dois ciclos para compensar esse efeito. Porém, não houve perda da qualidade do fruto em termos de diâmetro, pois para os frutos de banana do subgrupo Cavendish, que inclui o cv. Grande Naine, o diâmetro aceito como de boa qualidade varia entre 0,033 e 0,038 m, sendo de 0,034 m o ideal para exportação (Manica, 1997). No segundo ciclo, os valores dos parâmetros estudados foram semelhantes aos obtidos por Coelho et al. (2006a) em trabalho realizado em diferentes níveis de irrigação por microaspersão nos tabuleiros costeiros da Bahia.

No primeiro ciclo a produtividade média de pencas variou de 19,17 $\mathrm{t} \mathrm{ha}^{-1}$ a 21,10 $\mathrm{t} \mathrm{ha}^{-1}$ (Tabela 4), valores inferiores ao obtido por Melo et al. (2001), que registrou $48 \mathrm{t}$ ha- ${ }^{-1}$ no primeiro ciclo; isso ocorreu devido aos mesmos problemas relatados na avaliação do crescimento das plantas. No segundo ciclo houve aumento relevante da produtividade média em todos os tratamentos, entretanto essas produtividades ficaram abaixo dos valores obtidos por Souza et al. (2004) e Coelho et al. (2006b), que ficaram entre 54 e $62 \mathrm{t} \mathrm{ha}^{-1}$.

Houve efeito significativo dos tratamentos na produtividade e no diâmetro médio do fruto central da segunda penca no terceiro ciclo de produção. O tratamento T1 foi o que induziu a menor produtividade, tendo diferido significativamente do tratamento $\mathrm{T} 4$, que resultou na produtividade máxima. Os demais tratamentos não diferiram estatisticamente entre si pelo teste de Tukey a $5 \%$ de probabilidade (Tabela 4). Esses resultados foram diferentes dos obtidos por Souza et al. (2007), que usaram tratamentos semelhantes, com diferença apenas no uso da fonte amoniacal (sulfato de amônio) em vez da fonte amídica 
Tabela 3. Médias dos valores biométricos medidos na emissão do cacho no $1^{\circ} \mathrm{e} 2^{\circ}$ ciclos da bananeira cv. Grande Naine em diferentes combinações de uréia e nitrato de cálcio

\begin{tabular}{|c|c|c|c|c|c|c|}
\hline \multirow[b]{2}{*}{ Tratamento } & \multicolumn{3}{|c|}{$1^{\circ}$ ciclo } & \multicolumn{3}{|c|}{$2^{\circ}$ ciclo } \\
\hline & $\begin{array}{c}\text { Diâmetro de } \\
\text { pseudocaule } \\
\text { (m) }\end{array}$ & $\begin{array}{l}\text { Altura de } \\
\text { planta } \\
\text { (m) }\end{array}$ & $\begin{array}{l}\text { Área } \\
\text { foliar } \\
\left(\mathbf{m}^{2}\right)\end{array}$ & $\begin{array}{l}\text { Diâmetro de } \\
\text { pseudocaule } \\
\text { (m) }\end{array}$ & $\begin{array}{l}\text { Altura de } \\
\text { planta } \\
\text { (m) }\end{array}$ & $\begin{array}{c}\text { Área } \\
\text { foliar } \\
\left(\mathbf{m}^{2}\right)\end{array}$ \\
\hline $\mathrm{T} 1$ & 0,179 a & $1,84 \mathrm{a}$ & $8,51 \mathrm{ab}$ & 0,238 a & $2,58 \mathrm{a}$ & $13,76 \mathrm{a}$ \\
\hline $\mathrm{T} 2$ & 0,176 a & $1,81 \mathrm{a}$ & $8,41 \mathrm{ab}$ & 0,225 a & $2,45 \mathrm{a}$ & $12,75 \mathrm{a}$ \\
\hline T3 & 0,172 a & $1,81 \mathrm{a}$ & $8,33 \mathrm{~b}$ & 0,235 a & $2,54 \mathrm{a}$ & $12,95 \mathrm{a}$ \\
\hline $\mathrm{T} 4$ & $0,180 \mathrm{a}$ & $1,82 \mathrm{a}$ & $8,27 \mathrm{~b}$ & 0,230 a & $2,45 \mathrm{a}$ & $13,55 \mathrm{a}$ \\
\hline T5 & $0,180 \mathrm{a}$ & $1,85 \mathrm{a}$ & $8,95 \mathrm{~b}$ & 0,227 a & $2,43 \mathrm{a}$ & $13,90 \mathrm{a}$ \\
\hline T6 & $0,181 \mathrm{a}$ & $1,89 \mathrm{a}$ & 9,5 a & 0,237 a & $2,57 \mathrm{a}$ & $14,30 \mathrm{a}$ \\
\hline CV (\%) & 8,32 & 7,25 & 2,25 & 4,32 & 10,33 & 6,45 \\
\hline
\end{tabular}

Médias seguidas da mesma letra não diferem entre si, a 5\% de probabilidade, pelo teste de Tukey.

usada neste trabalho (ureia), não verificando efeito dos tratamentos na produtividade do mamoeiro. Entretanto, os autores verificaram que o tratamento que representava meio termo no uso da ureia e do nitrato de cálcio permitiu um custo menor ao produtor em relação ao uso único do nitrato e um efeito menor no solo quanto à redução de pH preconizada por diversos autores (Malavolta, 1981; MacLaren \& Cameron, 1996).

As Figuras 1 e 2 expressam o ajuste do modelo quadrático de regressão aos dados de produtividade em função das percentagens do nitrogênio na forma de ureia e de nitrato de cálcio, em que, confirmando as informações da Tabela 4, os pontos críticos para a percentagem de ureia situam-se em 36,1\%, e para o nitrato de cálcio em 65,1\%, que são os máximos das funções de produção obtidas.

O diâmetro médio do fruto da segunda penca foi influenciado pelos tratamentos, tendo o tratamento T6 diferido do tratamento T1 e apresentado maior valor com 0,037 m, enquanto o tratamento com $100 \%$ de ureia apresentou a menor média entre todos os tratamentos; isto é, 0,034 m (Tabela 4).
Como pode ser observado nos dados descritos na Tabela 5, o custo variável do uso dos fertilizantes nitrogenados ureia e nitrato de cálcio se eleva à medida que aumenta a utilização do nitrato de cálcio no ciclo da cultura, chegando a ser $760 \%$ maior, comparado ao tratamento em que é aplicado apenas ureia durante todo o ciclo. Em consequência, a margem bruta, determinada pela diferença entre a receita bruta e o custo variável, é menor quando se utiliza apenas o nitrato de cálcio (T6 = 7.705 R\$ $\mathrm{ha}^{-1}$ ), chegando a ser a metade da margem bruta proporcionada pela aplicação exclusiva com uréia. Isso é decorrente do alto custo do adubo nitrato de cálcio em relação à ureia. Para que se tenha uma margem bruta encontrada no T1, 100\% do ciclo com uréia, é necessário que se tenha aumento na produtividade nos tratamentos T2, T3, T4, T5 e T6 de aproximadamente 11, 17, 14, 45 e 44\%, respectivamente.

As avaliações da margem bruta levariam a se adotar o $\mathrm{T} 1$ como o de melhor resultado para o produtor, mesmo com a máxima produtividade no T4, cuja margem bruta é inferior em R\$2.673 por hectare.

Tabela 4. Médias de produtividade de pencas, número de frutos por cacho, comprimento da $2^{\circ}$ penca e diâmetro da $2^{\circ}$ penca em diferentes combinações de ureia e nitrato de cálcio em três ciclos de produção da bananeira cv. Grande Naine

\begin{tabular}{|c|c|c|c|c|c|c|c|c|c|}
\hline \multirow{3}{*}{ Tratamento } & \multicolumn{3}{|c|}{$\begin{array}{l}\text { Produtividade média } \\
\text { de pencas (ton ha-1) }\end{array}$} & \multicolumn{3}{|c|}{$\begin{array}{l}\text { Diâmetro médio do fruto } \\
\text { da } 2^{\circ} \text { penca }(\mathrm{m})\end{array}$} & \multicolumn{3}{|c|}{$\begin{array}{l}\text { Comprimento médio } \\
\text { do fruto da } 2^{\circ} \text { penca }(\mathrm{m})\end{array}$} \\
\hline & \multicolumn{3}{|c|}{ Ciclo } & \multicolumn{3}{|c|}{ Ciclo } & \multicolumn{3}{|c|}{ Ciclo } \\
\hline & $1^{\circ}$ & $2^{\circ}$ & $3^{0}$ & $1^{0}$ & $2^{\circ}$ & $3^{0}$ & $1^{0}$ & $2^{\circ}$ & $3^{\circ}$ \\
\hline $\mathrm{T} 1$ & $119,41^{\mathrm{ns}}$ & $36,56^{\mathrm{ns}}$ & 32,69 a & $0,202^{\text {ns }}$ & 0,216 ns & $0,222^{\text {ns }}$ & $0,034 \mathrm{~b}$ & $0,037^{\text {ns }}$ & $0,035 \mathrm{~b}$ \\
\hline $\mathrm{T} 2$ & $119,17^{\mathrm{ns}}$ & $35,24^{\mathrm{ns}}$ & $35,05 \mathrm{ab}$ & $0,218^{\text {ns }}$ & 0,221 ns & $0,213^{\text {ns }}$ & 0,036 a & $0,037^{\text {ns }}$ & $0,035 \mathrm{ab}$ \\
\hline T3 & $220,59^{\mathrm{ns}}$ & $35,96^{\mathrm{ns}}$ & $36,69 a b$ & $0,216^{\mathrm{ns}}$ & 0,211 ns & $0,215^{\mathrm{ns}}$ & $0,035 \mathrm{ab}$ & $0,037^{\text {ns }}$ & $0,035 \mathrm{ab}$ \\
\hline $\mathrm{T} 4$ & $119,46^{\mathrm{ns}}$ & $42,22^{\mathrm{ns}}$ & 39,86 a & $0,217^{\mathrm{ns}}$ & 0,225 ns & $0,225^{\mathrm{ns}}$ & $0,035 \mathrm{ab}$ & $0,037^{\text {ns }}$ & $0,037 \mathrm{ab}$ \\
\hline T5 & $119,86^{\mathrm{ns}}$ & $36,68^{\text {ns }}$ & $38,03 \mathrm{ab}$ & $0,213^{\text {ns }}$ & 0,216 ns & $0,219^{\text {ns }}$ & $0,036 \mathrm{ab}$ & $0,037^{\text {ns }}$ & $0,037 \mathrm{a}$ \\
\hline $\mathrm{T} 6$ & $21,10^{\mathrm{ns}}$ & $37,78^{\text {ns }}$ & $36,36 \mathrm{ab}$ & $0,298^{\text {ns }}$ & $0,218{ }^{\mathrm{ns}}$ & $0,220^{\text {ns }}$ & $0,0374 \mathrm{a}$ & $0,037^{\text {ns }}$ & $0,037 \mathrm{ab}$ \\
\hline CV (\%) & 10,06 & 14,85 & 9,30 & 3,92 & 4,28 & 4,12 & 2,53 & 3,8 & 2,28 \\
\hline
\end{tabular}

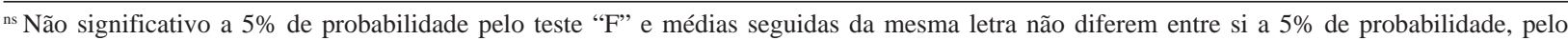
teste de Tukey. 


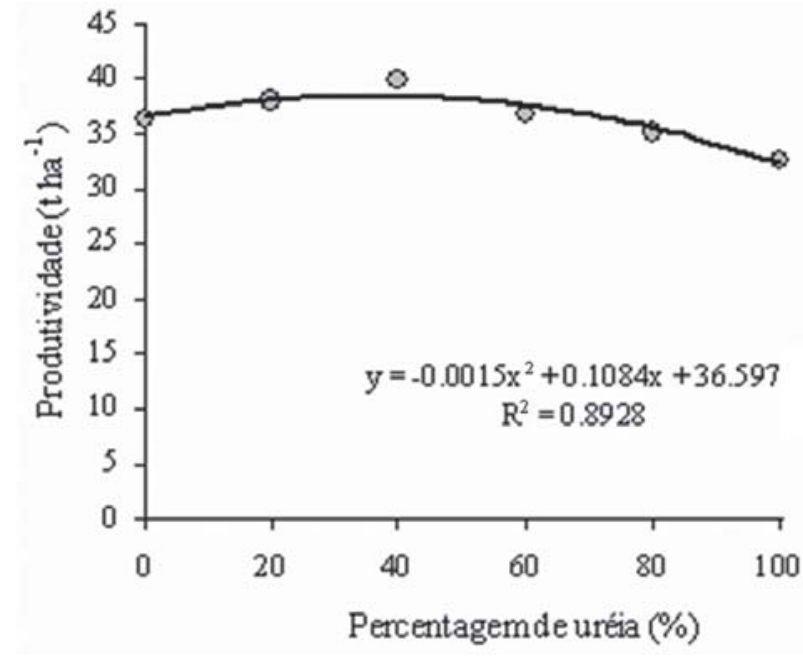

Figura 1. Produtividade da bananeira cv. Grande Naine em função da percentagem de ureia aplicada via fertirrigação.

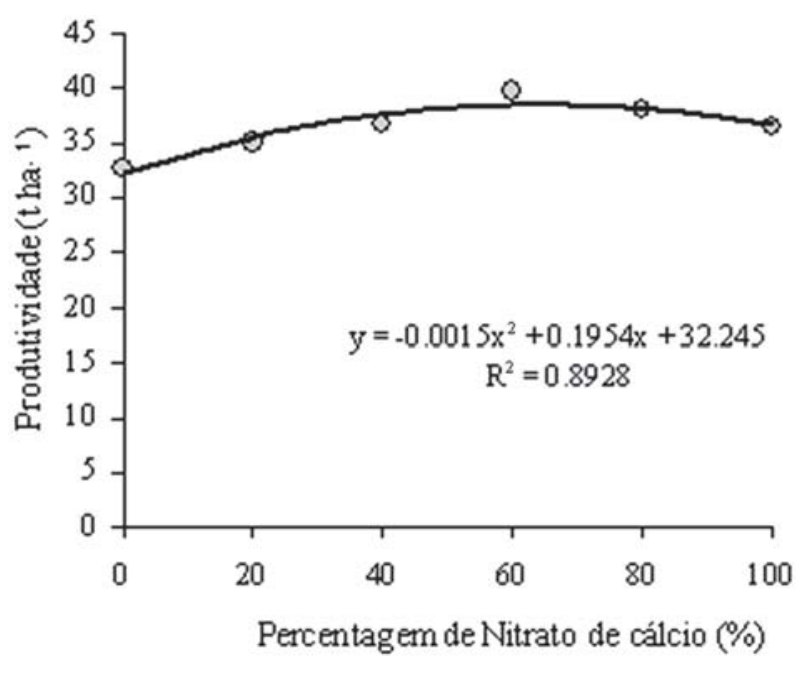

Figura 2. Produtividade da bananeira cv. Grande Naine em função da percentagem de nitrato de cálcio aplicado via fertirrigação.

Tabela 5. Custo variável (R \$/ha), produtividade média (t/ha), receita bruta (R $\$ / h a)$ e margem bruta (R \$ha) da combinação das fontes nitrogenadas para cada tratamento para os dois ciclos de produção da bananeira Grande Naine. Valores de dez./2007

\begin{tabular}{|c|c|c|c|c|c|}
\hline Tratamento & $\begin{array}{c}\text { Custo Variável } \\
\left(\mathrm{R} \$ \mathrm{ha}^{-1}\right)\end{array}$ & $\begin{array}{l}\text { Produtividade } \\
\quad\left(\text { ton ha }{ }^{-1}\right)\end{array}$ & $\begin{array}{c}\text { Preço } \\
\left(\mathrm{R} \$ \text { ton }^{-1}\right)\end{array}$ & $\begin{array}{c}\text { Receita Bruta } \\
\left(\mathbf{R} \$ \text { ha }^{-1}\right)\end{array}$ & $\begin{array}{c}\text { Margem bruta } \\
\left(\mathrm{R} \$ \text { ha }^{-1}\right)\end{array}$ \\
\hline $\mathrm{T} 1$ & 1.311 & 55,97 & 300 & 16.791 & 15.480 \\
\hline $\mathrm{T} 2$ & 2.563 & 54,42 & 300 & 16.327 & 13.764 \\
\hline T3 & 4.445 & 56,56 & 300 & 16.968 & 12.523 \\
\hline $\mathrm{T} 4$ & 5.698 & 61,68 & 300 & 18.505 & 12.807 \\
\hline T5 & 8.369 & 54,55 & 300 & 16.364 & 7.995 \\
\hline $\mathrm{T} 6$ & 9.962 & 58,89 & 300 & 17.666 & 7.705 \\
\hline
\end{tabular}

\section{CONCLUSÕES}

As diferentes combinações das fontes nitrato de cálcio e ureia aplicadas por fertirrigação não tem efeito sobre as variáveis de crescimento: diâmetro do pseudocaule e altura da planta da bananeira cv. Grande Naine.

O nitrato de cálcio não altera as características vegetativas ou produtivas da cultura, além de aumentar o custo de produção. Portanto, seu uso não é vantajoso.

Não há efeito das diferentes combinações de aplicação das fontes nitrogenadas sobre a produtividade média de pencas, número médio de frutos por cacho e comprimento médio do fruto da segunda penca.

\section{REFERÊNCIAS}

Alves AAC, Silva Junior JFS \& Coelho EF (2001) Estimation of banana leaf area by simple and non-destructive methods. In: Congresso Brasileiro de Fisiologia Vegetal, Ilhéus. Anais, CD-ROM.

Barbosa Filho MP, Fageria NK \& Silva OF (2004) Fontes e métodos de aplicação de nitrogênio em feijoeiro irrigado submetido a três níveis de acidez no solo. Ciência e Agrotecnologia, 28:785-792.

Borges AL (2004) Recomendação de adubação para a bananeira. Cruz das Almas, Embrapa Mandioca e Fruticultura Tropical, 4p. (Embrapa CNPMF, Comunicado Técnico 106).
Borges AL \& Coelho EF (2002) Fertirrigação da bananeira. Cruz das Almas, Embrapa Mandioca e Fruticultura, 4p. (Embrapa CNPMF, Comunicado Técnico 74).

Borges AL \& Costa EL (2002) Requerimentos de nutrientes para fertirrigação - banana. In: Borges AL, Coelho EF, Trindade AV (Orgs.) Fertirrigação em fruteiras tropicais. Cruz das Almas, Embrapa Mandioca e Fruticultura, p.77-84.

Borges AL, Silva TO, Caldas RC \& Almeida IE (2002) Adubação nitrogenada para bananeira-'Terra' (Musa sp. AAB, subgrupo terra). Revista Brasileira de Fruticultura, 24:189-193.

Borges AL, Silva JTA \& Oliveira SL (1997) Adubação nitrogenada e potássica para bananeira $c v$. 'Prata Anã': produção e qualidade dos frutos no primeiro ciclo. Revista Brasileira de Fruticultura, 19:179-184.

Brasil EC, Oeiras AHL, Menezes AJEA \& Veloso CAC (2000) Desenvolvimento e produção de frutos de bananeira em resposta à adubação nitrogenada e potássica. Pesquisa Agropecuária Brasileira, 35:2407-2414.

Coelho AM (1994) Fertigação. In: Costa EF, Vieira RF \& Viana PA (Ed.) Quimigação. Sete Lagoas, EMBRAPA/CNMS. p.201-27.

Coelho EF, Costa EL, Ledo CAS \& Silva SO (2006a) Produtividade e eficiência do uso de água das bananeiras 'Prata Anã' e 'Grande Naine' no terceiro ciclo sob irrigação por microaspersão em tabuleiros costeiros da Bahia. Revista Brasileira de Fruticultura, 28:435-438.

Coelho EF, Ledo CAS \& Silva SO (2006b) Produtividade da bananeira 'Prata Anã' e 'Grande Naine' sob irrigação no terceiro ciclo no norte de Minas Gerais. Irriga, 11:460-468. 
Coelho EF, Andrade CLT, Or D, Lopes LC \& Souza CF (2001) Desempenho de diferentes guias de ondas para uso com o analisador de umidade Trase. Revista Brasileira de Engenharia Agrícola e Ambiental, 5:81-87.

D’Angiolella GLB, Castro Neto MT \& Coelho EF (1998) Tendências climáticas para os tabuleiros costeiros da região de Cruz das Almas. In: Congresso Brasileiro de Engenharia Agrícola, Poços de Caldas. Anais, Lavras, SBEA. p.43-45.

Doorembos J \& Kassam AH (1979) Yield response to water. Rome, FAO (Irrigation and Drainage Paper 33), 306p.

Doorembos J \& Pruitt WO (1977) Crop water requirements. Rome, FAO (Irrigation and Drainage Paper 24), 194p.

Haynes RJ \& Swift RS (1987) Effect of trickle fertigation with three forms of nitrogen on soil $\mathrm{pH}$, levels of extractable nutrients below the emitter and plant growth. Plant and Soil, 102:211-221.

IBGE - Instituto Brasileiro de Geografia e Estatística (2007) Levantamento Sistemático da Produção Agrícola. Disponível em: <http://www.ibge.gov.br/home/estatistica/indicadores/ agropecuaria/lspa/default.shtm> Acessado em: 21 de dezembro de 2008.

Lahav E \& Turner D (1983) Banana nurition. Bern, International Potash Institute, 62p. (IPI-Bulletin 7).

Ledieu J, De Ridder P, De Clerck P \& Dautrebande S (1986) A method for measuring soil water moisture by time-domain reflectometry. Journal of Hydrology, 88:319-328.

MacLaren RG \& Cameron KC (1996) Soil, plant and fertilizer nitrogen. In: Mclaren RG (Ed.) Soil science: Sustainable production and environmental protection. 2.ed. New York, Oxford University Press. p.192-207
Malavolta E (1981) Manual de química agrícola: adubos e adubação. $3^{\mathrm{a}}$ ed. São Paulo, Agronômica Ceres. 594p.

Manica I (1997) Fruticultura tropical: 4 banana. Porto Alegre, Cinco Continentes. 485p.

Melo FB, Cardoso MJ, Andrade Júnior AS \& Ribeiro VQ (2001) Produtividade da banana 'Grande Naine' sob adubação química. In: Simpósio de Inovações Tecnológicas e Gerenciais, Fortaleza. Anais, Fortaleza: Frutal, Embrapa Agroindústria Tropical. CD-ROM.

SAS Institute Inc. (2000) SAS/STAT user's guide. Cray NC. V.1-3.

Silva SO, Alves EJ, Shepherd K \& Dantas JLL (1999) Cultivares. In: Alves EJ (Org.) A cultura da banana: Aspectos técnicos, socioeconômicos e agroindustriais. Brasília, EMBRAPA-SPI. p. 85-105.

Silva SO, Rocha AS, Alves EJ, Credico MD \& Passos AR (2000) Caracterização morfológica e avaliação de cultivares e híbridos de bananeira. Revista Brasileira de Fruticultura, 22:161-169.

Sousa VF, Veloso ME, Vasconcelos LFL, Ribeiro VQ, Souza VAB \& Albuquerque Júnior BS (2004) Nitrogênio e potássio via água de irrigação nas características de produção da bananeira 'Grande Naine’. Pesquisa Agropecuária Brasileira, 39:865-869.

Souza LS \& Souza LD (2001) Caracterização físico-hidrica de solos da área do Centro Nacional de Pesquisa de Mandioca e Fruticultura Tropical, Cruz das Almas, Bahia. Cruz das Almas, EMBRAPA-CNPMF. 56p. (Boletim de pesquisa 20).

Souza TV, Paz VPS, Coelho EF, Pereira FAC \& Ledo CAS (2007) Crescimento e produtividade do mamoeiro fertirrigado com diferentes combinações de fontes nitrogenadas. Irriga, 12:563-574.

Thornley JHM (1972) A balanced quantitative model for root: shoot ratios in vegetative plants. Annals of Botany, 36:431-441. 